\title{
ELECTROCHEMICAL HONING - A NOVEL TECHNIQUE FOR GEAR FINISHING
}

\author{
MiSRA, J. P.; JAIN, P. K. \& DWIVEDI, D. K.
}

Abstract: This paper reports on high-precision finishing of gears by Electrochemical Honing (ECH) process. It is one of the most potential micro-finishing process in which material is removed by anodic dissolution combined with mechanical abrasion of bonded abrasive grains. The precision finishing of gears by ECH is a productive, high accuracy, long tool life gear finishing process. The present study contains a detailed description of the process principle, influencing parameters, process capabilities, equipment details, applications, effects of input parameters, developed regression models, surface integrity aspects of machined surface and comprehensive literature review of past research work on the ECH of gears along with some guidelines for further research with an objective to revive the interest of the global research community to mature this process further.

Key words: ECM, honing, ECH, gear failure, surface integrity
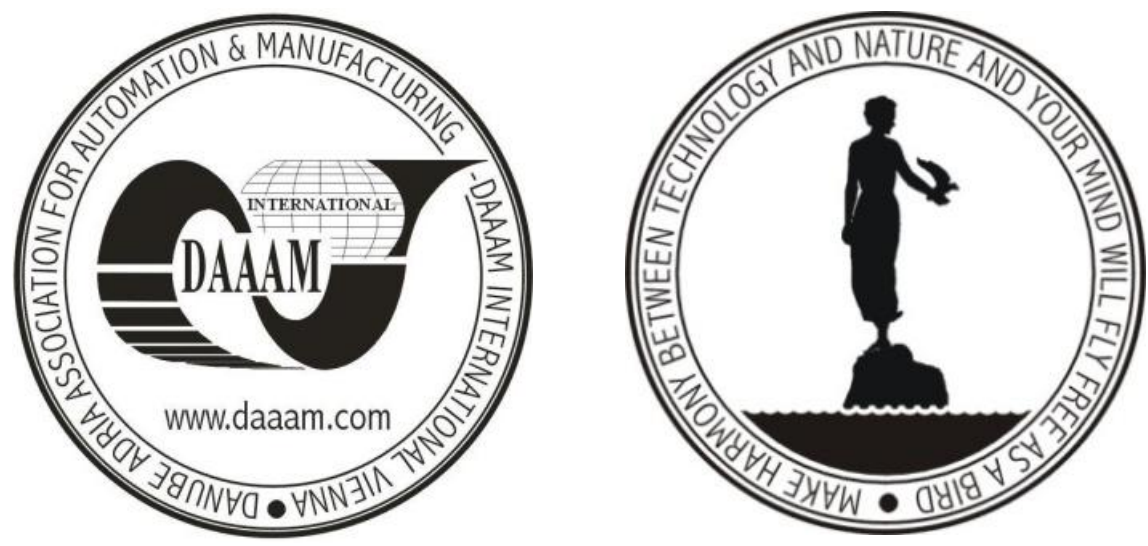

Authors' data: Misra, J[oy] $\mathrm{P}[\mathrm{rakash}]$; Jain, $\mathrm{P}[\mathrm{ramod}] \mathrm{K}[\mathrm{umar}]$; Dwivedi, D[heerendra] K[umar], Mechanical \& Industrial Engineering Department, Indian Institute of Technology Roorkee, India, joyprakash.misra@gmail.com, misradme@iitr.ernet.in

This Publication has to be referred as: Misra, J[oy]; Jain, P[ramod] K[umar] \& Dwivedi, D[heerendra] K[umar] (2011). Electrochemical Honing - a Novel Technique for Gear Finishing, Chapter 29 in DAAAM International Scientific Book 2011, pp. 365-382, B. Katalinic (Ed.), Published by DAAAM International, ISBN 978-3-901509-84-1, ISSN 1726-9687, Vienna, Austria

DOI: $10.2507 /$ daaam.scibook.2011.29 


\section{Introduction}

Gears are vital elements for Mechanical Industries to transmit power and/or motion most efficiently between two shafts by means of gradual engagement of the teeth positively, i.e. without slip so that connecting shafts can rotate at constant velocity ratio. Depending on their construction and arrangement, geared devices can transmit forces at different speeds, torques from the power source to the same or different direction. Gears can be classified according to three criteria namely (1) according to configuration: external and internal gears; (2) according to axes of transmission: (a) for transmission between parallel shafts: straight toothed spur gear, single helical, and double helical or Herringbone gears, (b) for transmission between intersecting shafts: bevel gears (straight-tooth, spiral-tooth, zero-bevel, crown, and miter type), (c) for transmission between nonparallel and non-intersecting shafts: spiral gears, hypoid gears, worm and worm wheel; and (3) according to pattern of rotation: (a) rotation to rotation, (b) rotation to translation and vice-versa (i.e. rack and pinion) (Dudley, 1984). Toothed gears are made in a great variety of forms and sizes, varying from the tiny pieces used in a wrist watches to the $6.01 \mathrm{~m}$ diameter monsters used aboard ship for reducing the high speed of the turbine shaft to the low speed of the proposed shaft. The application areas of gears are also vast and it include small gears in precision equipments, clocks, watches, robots and toys, gears for office equipments, appliance gears, machine tool gears, control gears, automotive, transportation, marine and aerospace gears, gears for oil and gas industry, large and heavy duty gear boxes used in cranes, conveyors, construction equipment, agricultural, and defense equipment, gears for large mills used for producing cement, grind iron ore, rubber, roll steel, etc. (Davis, 2005).

Annually 2-3 billion gears are consumed worldwide with a turnover running into several billion Euros. Moreover, it is found from an anonymous survey of gear manufacturers that $70 \%$ expect gear sales volume to increase in 2011. Despite of excellent market position there are increasing requirements for further improvement of gear drives, as mentioned by Goch (2003), which include: (i) Improvement of power density and transmitted power, (ii) Reduction in running noise, toxic emission, and price, (iii) Increase in reliability and service life time, (iv) Easy disposal and material recycling of the used gears, and (v) Integration of electronic systems such as data acquisition, logical control, integrated safety system, etc. Gear teeth can fail in many different ways and except for an increase in noise level and vibration, often there is no indication of difficulty until total failure occurs. Gear teeth are vulnerable to two types of failure namely non-lubrication related failures and lubrication related failures. Non-lubrication related failures include overload and bending fatigue types of failure. Lubrication related failures include Hertzian fatigue, wear and scuffing. Table 1 represents the different modes of gear tooth failure according to Davis (2005). One of the main reasons behind these different gear failure modes is poor surface finish of the gear teeth. To prevent premature failure of gear teeth, careful consideration requires for the interrelationship among the following factors: gear 
tooth geometry, gear tooth motion, gear tooth forces (static and dynamic), gear tooth material, lubricant characteristics (physical and chemical), operating environment and surface characteristics. The first six items are related to the design and application of gears while the last item depends on the gear finishing methods. Poor surface quality of gear teeth profiles causes the gears running at high speed and transmitting large power being subjected to additional dynamic forces. Therefore, the gear teeth surface must be smooth and error-free for smooth, noiseless power and/or motion transmission and to improve the load carrying capacity. The errors related to gear profile and its surface quality can be reduced significantly by the gear finishing processes. Karpuschewski et al. (2008) classified the goals of gear finishing into two categories namely (i) improvement in surface quality and reduction in form errors to maximize load capacity and (ii) flank modifications and improving surface integrity to minimize the running noise.

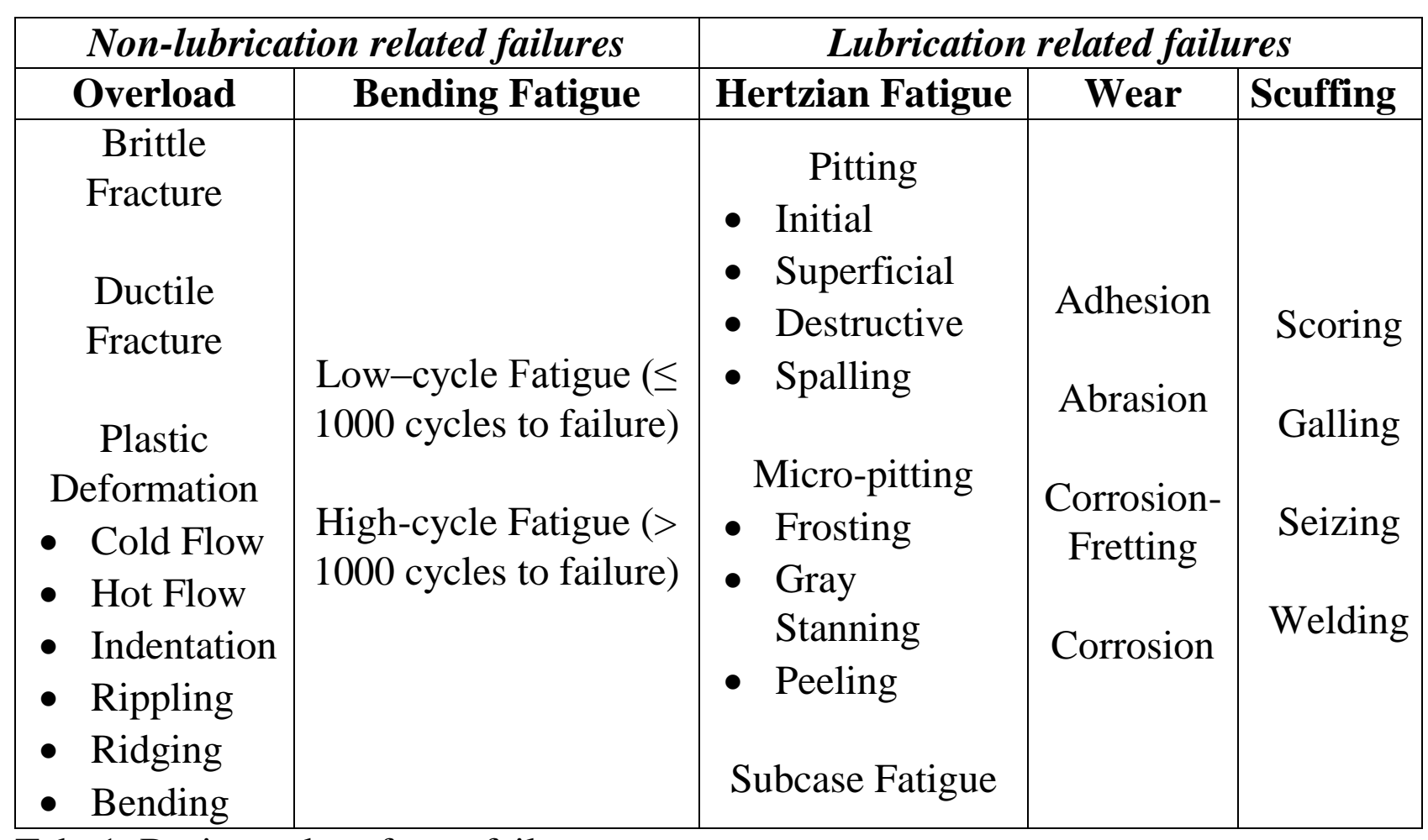

Tab. 1. Basic modes of gear failures

To improve the surface quality of gear teeth profile, the discontinuities such as small pits, burrs, scratches, cut marks, etc. of gear teeth profile should be reduced by finishing of gears. Conventional processes namely gear grinding, gear shaving, gear honing, gear lapping, etc. are very much popular in industries. But, these conventional processes are costly, time consuming and having material hardness limitation. These shortcomings necessitate the exploration of advanced gear finishing processes such as electrochemical honing $(\mathrm{ECH})$ of gears, ultrasonic assistance lapping, etc. It is reported that, in terms of productivity and the surface finish achieved, the ECH process is better than all the processes (Benedict, 1987; Wei, 2007). 
Electrochemical honing $(\mathrm{ECH})$ has capabilities and potential to be developed as an alternative of conventional gear finishing processes and can play an important role as high-precision gear finishing method because being a hybrid machining process it has potential to overcome most the limitations of conventional gear finishing methods and at the same time offers most of the capabilities of the conventional gear finishing methods.

\section{Overview of ECH}

Electrochemical Honing $(\mathrm{ECH})$ is one of the most potential hybrid electrochemical-mechanical process, is based on the interaction of Electrochemical Machining (ECM) and mechanical honing. In ECH, most of the material is removed by electrolytic dissolution action of ECM. But during ECM, a thin micro-film of metal oxide is formed on the workpiece. This film is insulating in nature and protects the workpiece surface from further being removed. With the help of bonded abrasives, honing acts as scrubbing agent to remove the thin insulation layer from high spots and thus produces fresh metal for further electrolytic dissolution. The typical range of process parameters for $\mathrm{ECH}$ is given below in Table 2.

\begin{tabular}{|l|l|}
\hline \multicolumn{1}{|c|}{ Power Supply } & \multicolumn{1}{c|}{ Electrolyte } \\
\hline & Type: $\mathrm{NaNO}_{3}, \mathrm{NaCl}$ \\
Type: $\mathrm{DC}$ & Concentration: $120 \mathrm{~g} / \mathrm{L}\left(\mathrm{NaNO}_{3}\right), 240 \mathrm{~g} / \mathrm{L}(\mathrm{NaCl})$ \\
Voltage: $6-30 \mathrm{~V}$ & Temperature: $25-38^{\circ} \mathrm{C}$ \\
Current: $100-3000 \mathrm{~A}$ & Pressure: $500-1000 \mathrm{kPa}$ \\
Current density:15.5-465 A/cm & Flow rate: $\mathrm{Upto} 95 \mathrm{~L} / \mathrm{min}$ \\
& IEG: $0.076-0.25 \mathrm{~mm}$ \\
\hline
\end{tabular}

Tab. 2. Typical value of ECH Parameters (Machining Data Handbook, 1980)

\subsection{ECM Process}

The electrolytic material removal in ECM is based on the Faraday's laws of electrolysis, details of which are available in standard text books (Wilson, 1971; Pandey, 1980). Electrolysis occurs when an electric current passes between two electrodes dipped into an electrolyte solution and due to which chemical reactions occur at electrodes. This chemical reaction is known as anodic or cathodic reaction or in a single word Electrochemical Dissolution (ED). ED of anodic workpiece is the basis for electrochemical machining of metals. A schematic of the conventional ECM process is presented in Fig. 1. ECM process uses an electrolyte that completes the electric circuitry between anodic workpiece and cathodic tool and prevents the anodic material from being deposited on cathode. Thus, it is reverse process of electroplating. For an example, the dissolution reactions of iron in $\mathrm{NaCl}$-water solution produce hydrogen gas at cathode and dissolution of iron from anode (McGeough, 1974). The various reactions that occur during ED are given below.

- The dissolution of $\mathrm{NaCl}$-water solution provides: 


$$
\begin{aligned}
& \mathrm{H}_{2} \mathrm{O} \rightarrow \mathrm{H}^{+}+\mathrm{OH}^{-} \\
& \mathrm{NaCl} \rightarrow \mathrm{Na}^{+}+\mathrm{Cl}^{-}
\end{aligned}
$$

- The anions $\mathrm{OH}^{-}$and $\mathrm{Cl}^{-}$move towards the anode and cations $\mathrm{H}^{+}$and $\mathrm{Na}^{+}$move towards cathode.

- Anode Reaction: Fe changes to $\mathrm{Fe}^{++}$by releasing two electrons in solution

$$
\mathrm{Fe} \rightarrow \mathrm{Fe}^{++}+2 \mathrm{e}
$$

- Cathode Reaction: Involves the generation of hydrogen gas and hydroxyl ions

$$
2 \mathrm{H}_{2} \mathrm{O}+2 \mathrm{e} \rightarrow \mathrm{H}_{2}+2(\mathrm{OH})^{-}
$$

- Final Outcome: Fe precipitates out as $\mathrm{Fe}(\mathrm{OH})_{2}$

$$
\mathrm{Fe}+2 \mathrm{H}_{2} \mathrm{O} \rightarrow \mathrm{Fe}(\mathrm{OH})_{2} \downarrow+\mathrm{H}_{2} \uparrow
$$

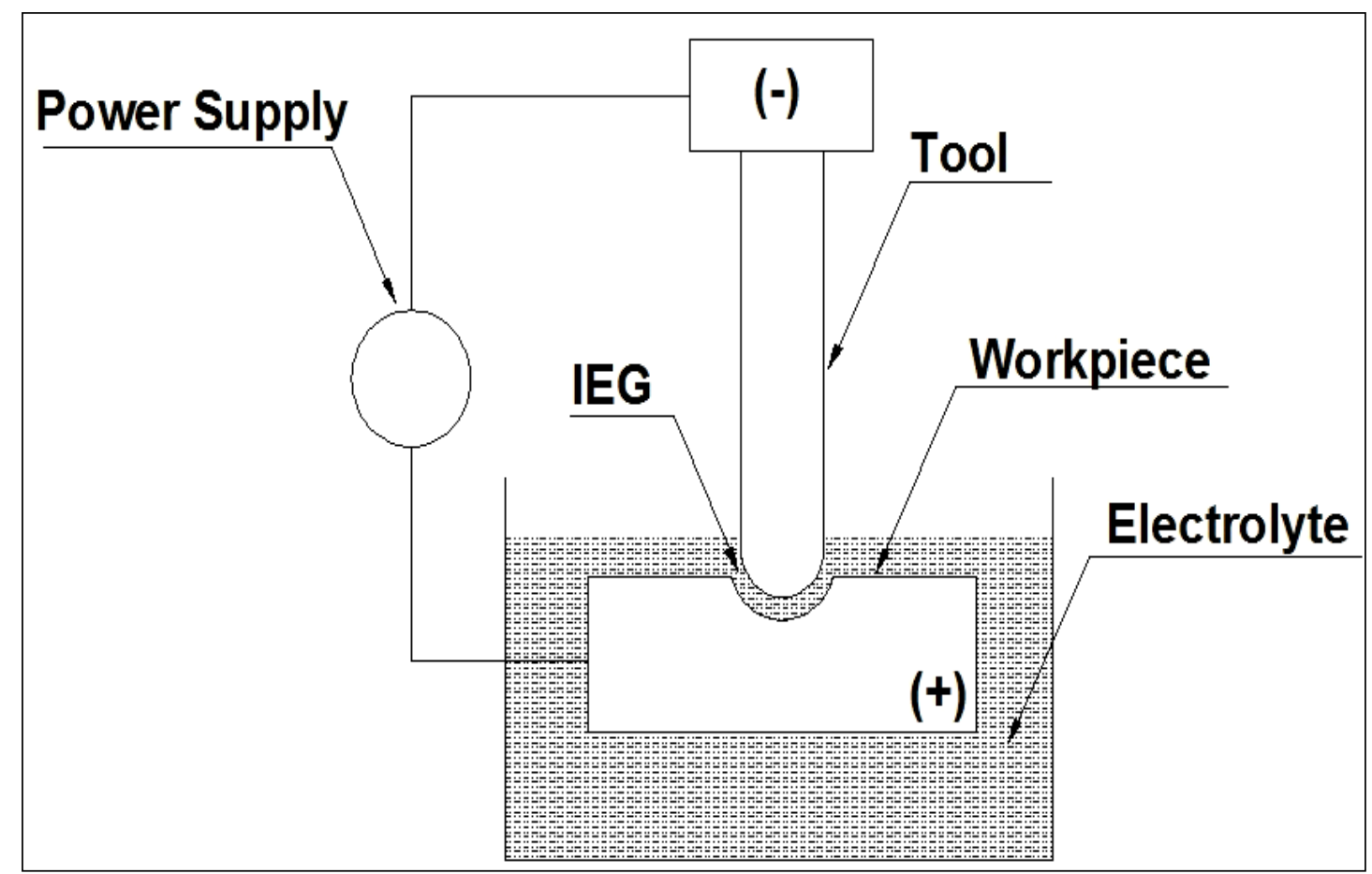

Fig. 1. Schematic of ECM Process

The electrolyte removes the dissolution products, such as metal hydroxides, heat, and gas bubbles, generated in the inter electrode gap (Ei-Hofi, 2005). The ECM can process complex cavities in high-strength materials and produces burr-free surfaces. There is no direct contact between tool and workpiece which results in no tool wear. Various industrial techniques have been developed on the basis of this ECM principle such as electrochemical drilling, electrolytic jet drilling, shaped tube electrolytic machining, etc.

\subsection{Honing}

Honing is a subtractive type manufacturing process in which material is removed by the cutting action of bonded abrasive grains and is used to improve the form, dimensional precision and surface quality of a workpiece under constant surface contact with the tool. In general, honing is applied after precision machining (e.g. grinding). Different honing techniques namely longitudinal stroke honing is 
used for connecting rod holes, brake drum, cylinder liners, etc.; shortstroke honing is used for crank shaft, rotor shaft; profile honing is used for tracks of inner and outer ball bearing rings; surface honing for finishing roller guideways, guide rails; gear honing, etc. are commonly used in Industries. However, honing procedures are divided into three main groups: longitudinal stroke honing frequently referred to as honing; shortstroke honing, frequently designated as fine honing or superfinishing and gear honing (Klocke, 2009). The longitudinal stroke honing or honing can be applied to internal cylindrical surfaces with a wide range of diameters namely engine cylinders, bearing bores, pin holes, etc. and also to some external cylindrical surfaces (Oberg et al, 2008). This is employed not only to produce high finish, but also to correct out of roundness, taper, boring tool marks, bell mouth and barrel and axial distortion in workpieces.

In ECH of gears, the principle of gear honing is used. The gear-tooth-honing process is a large volume production finishing operation that removes small amounts of material to improve the surface finish. It a hard-gear-finishing method that was developed to improve the sound characteristics of hardened gears. The process, resembling shaving, employs an abrasive-impregnated plastic helical gear-shaped tooth. Recently, steel hones coated with bonded sintered tungsten carbide grit have become available and offer longer life. Plastic hones are less expensive and are therefore still best for small production runs. In this process, the work gear, driven by the tool on crossed-axes, is reciprocating across the hone. The honing tool drives the gear alternately in both directions. Since it is an abrasive action, it is particularly suited for refinement of hardened teeth. Gear honing, because of its economical feasibility, has become an essential part in the production of high-speed transmissions. This is especially true in the automotive and truck industry as honed gears, in comparison to ground gears, are extremely quiet and have excellent wear characteristics due to their typical surface finish. Honed gears produce less noise and have a longer use life than other gears due to their typical surface structure. The structure of the surface of a honed gear, which resembles a fish skeleton, facilitates the formation of a lubrication film surface from the tip of the flanks to the pitch diameter and thereby positively influences the noise behaviour in the gearbox.

\subsection{Applications of ECH}

ECH can be employed to produce precision finishing and improved surface integrity. As in $\mathrm{ECH}$, most of the material is removed by ECM action, the process keeps the workpiece cool, free of heat distortion and produces burr and stress free surfaces. The rotating and reciprocating honing motion correct shape deviations of cylindrical workpieces such as circularity, taper, bell-mouth hole, barrel-shaped hole, axial distortion, and boring tool marks. However, ECH cannot correct location of hole or perpendicularity. ECH has no material hardness limiting factor as long as the material is electrically conductive. Cast tool steels, high-alloy steels, carbide, titanium alloys, Incoloy, Stainless steel, Inconel, etc. are typical list of materials that can be processed by ECH. This process is an ideal choice for increasing the lifecycle of the critical components such as internal cylinders, transmission gears, carbide 
bushings and sleeves, rollers, petrochemical reactors, moulds and dies, gun barrels, pressure vessels, etc. which are made of very hard and/or tough, wear-resistant materials, most of which are prone to heat distortions and as a result, $\mathrm{ECH}$ has wide application area including automobile, avionics, petrochemical, power generation, machine tool and fluid power industries. (Machining Data Handbook, 1980; Drozda, 1983; Bralla, 1986). ECH of gears is an extended application of ECH initiated by Capello and Bertoglio (1979). The ECH of gears has huge potential to correct the gear teeth profile errors of different types of gears while providing precision finishing to them. Moreover, gear teeth are like cantilever beam and therefore the maximum stress is generated at the root portion of the teeth. Discontinuities, scratches, notches present at active profile (i.e., root or flank position) of gear teeth encourage the chances of fatigue failure of gears. The improvement in surface finish of root portion enhances the fatigue life and thus the process is highly applicable for gear using industries to improve the in-service performances.

\section{ECH of Gears}

$\mathrm{ECH}$ is an electrochemical (EC) based hybrid machining process combining the electrochemical machining (ECM) process and conventional honing. ECM provides the faster material removal capability and honing provides the controlled functional surface generating capabilities. This process is five to ten times faster than conventional honing and four times faster than grinding (Drozda, 1983). Moreover, the process can provide surface finish upto $0.05 \mu \mathrm{m}$ (Benedict, 1987) which is also far better than other non-traditional gear finishing processes (e.g., ultrasonic assisted lapping $\left[\mathrm{R}_{\mathrm{a}}=0.2 \mu \mathrm{m}\right]$ ) (Wei, 2007).

\subsection{Process Principle}

Fig. 2 describes the working principle of ECH of gears, first proposed by Chen et al. (1981). As shown in Fig. 2, the workpiece gear, simultaneously rotating and reciprocating as indicated by the arrow heads, is meshed with the abrasive bonded honing gear and specially shaped cathode gear. A proper electrolyte is flooded in between the anodic workpiece gear and negative cathode gear. A gap is provided between workpiece and cathode gear as inter electrode gap (IEG) to prevent short circuit.

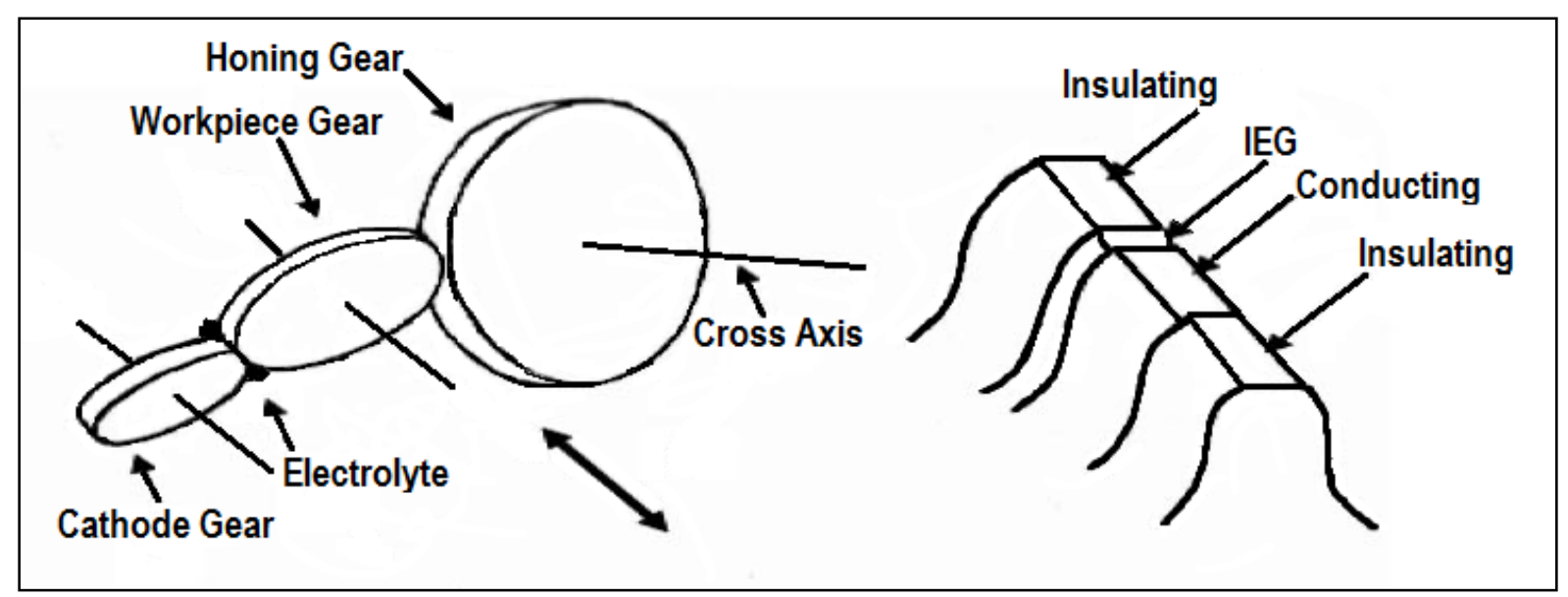

Fig. 2. The working principle of ECH of gears explained by Chen et al. (1981) 
As DC supply is applied across the gap, the metal starts removing from workpiece due to EC dissolution. But the electrolyte selected should be such that, the metal removing from the workpiece gear must be precipitate without depositing on cathode gear. The electrolyte, however, during the process of metal removing from the flank, due to electrolyte passivation, a protective film is formed on the tooth surface which protects the surface from being further removed. This metal oxide microfilm protected tooth profile when comes into contact of honing gear, honing gear scrubs the protective film from the high spots and produces fresh metal for further EC dissolution. The honing gear is mounted on a floating stock to ensure dual flank contact of hone and gear. It is much like the dual flank checking process, those high spots both along the tooth face and along the involutes profile will be scraped free from the protective coating. These extruding high spots, when come again into the EC zone, will be electro-chemically removed once again. Thus the process carries on alternatively and the geometric accuracy is rapidly improved.

\subsection{Process Parameters}

$\mathrm{ECH}$ of gears is a hybrid machining process of ECM and conventional honing process and hence, its parameters include the parameters related to ECM and conventional honing in addition some parameters related to workpiece and tooling. The process parameters of ECH can be broadly classified into four groups (Dubey, 2006):(a) Power supply related parameters: operation mode (constant or pulse), current, voltage, pulse-on time, and pulse-off time; (b) Electrolyte related parameters: composition, concentration, pressure, temperature, flow rate, conductivity, and $\mathrm{pH}$ value; (c) Honing related parameters: type of abrasive, abrasive particle size, type of bond, rotary speed, and reciprocating speed; (d) Workpiece related parameters: electrolytic and mechanical properties of workpiece, size of workpiece, rotating speed of workpiece and IEG (i.e. undercut of the profile of conducting gear in sandwiched cathode gear).

\section{Literature Review}

The general principle of anodic metal removal was one of the discoveries of Michael Faraday (1791-1867) from which stemmed the development of electrochemical processes. Electrochemical machining turns out to have been first proposed in 1929, when a Russian, W. Gusseff, filed a patent for an electrochemical machining process with many features almost identical to the process as now practiced. Furthermore an American, Burgess, had demonstrated the possibilities of the process in 1941. He drew attention to the striking difference between the mechanical and electrolytic methods of removing metal. But, it was not until 1959 that the phenomenon of controlled anodic metal removal, a basis for all electrochemical process, was put forward in the form of a commercial apparatus for the regular industrial application of electro-chemical machining (ECM) by Anocut Engineering company of Chicago. The electrolytic applications to conventional 
honing started in 1962-1963 (Horgan, 1962; Eshelman, 1963). Initially the purpose of electrolytic aid to conventional honing was just to improve the process productivity owing to the higher material removal achieved by the conventional honing process itself (Wilson, 1971). According to the best knowledge of authors, Budzynski (1978, 1980) is probably the first researcher who carried out research on ECH with his publications on ECH machine and theoretical details and technical factors of ECH after it is initiated by Randlett and Ellis $(1967,1968)$. But, the application of ECH for gear finishing was started in 1979 by Capello and Bertoglio as they described the $\mathrm{ECH}$ for finishing the hardened cylindrical gear tooth face. The development of a productive, high-accuracy, long tool life, gear finishing method was described by Chen et al. (1981). The total works were done in the field of checking the ability of correcting geometrical error in ECH of gears, its principle and methods of improving. They explained the problem of high quality gear manufacturing to smooth running at high speed. The paper explained the process consisting of a workpiece gear reciprocating axially and rotating in mesh with a sandwiched cathode gear and a honing gear. The ECM action takes place between the anode workpiece and the cathode gear. The cross-axis honing gear which mounted on a floating stock to maintain dual flank contact with work gear, scrubs the protective oxide film from high spots leading heavier electrochemical (EC) action when they come into EC zone. Thus geometric accuracy in the workpiece gear tooth profile is rapidly improved. Wei et al. (1986) described that ECH is a fine machining process and a means to produce excellent surface quality. They showed by the experiment that if the protective ability of oxide film on the workpiece surface could be fully utilized, and a distinct mechanical scrubbing trace on the workpiece can be guaranteed, it could become a means to correct geometric inaccuracy too. In this case, EC is used mainly for material removal and honing for mechanical scrubbing only. If a right electrolyte and mechanical scrubbing means can be selected, it could become a precision machining method with very distinguished feature.

Material removal in ECH is governed by Faraday's law of electrolysis, according to which the material removed/deposited is proportional to the amount of electric charge (i.e. amount of current multiplied by time duration), the amount of material removed and consequently the accuracy of the gear profile can be controlled either by controlling the amount of current passed or by varying the process duration. Wei et al. (1987) used a current control method by varying the intensity of the electric field to control the intensity of electrolytic dissolution steplessly along the full profile of the gear using a newly developed gear-shaped cathode in the fieldcontrolled ECH (FC-ECH) of gears. While, He et al. (2000) used the time-control method to correct the gear tooth profile errors very efficiently in a process that they called slow-scanning field-controlled ECH (SSFC-ECH) of gears. Yi et al. (2000) described the electrochemical gear tooth profile-modification theory. They mentioned a new process of axial modification for carbonized gears and investigated the current density distribution in the gear teeth. Their test result indicated that both current and processing periods are principal parameters to affect the volume of crown and the 
amount of modification. Yi et al. (2002) explained a new method for electrochemical tooth-profile modification based on real-time control and established a mathematical model of the electrochemical tooth profile modification process using an artificial neural network. In 2009, Yi et al. described the processing mechanism of Pulse Electrochemical Mechanical Polishing (PECMP) and the effects of its influencing factors. PECMP is combined by pulse electrochemical and mechanical action to reduce the surface roughness value to $R_{a} 0.02 \mu \mathrm{m}$ and lower to meet the requirement of gear work-surface polishing. They investigated the effects of electrolyte (electrolyte composition, electrolyte concentration, and electrolyte temperature), current density, speed, press and revolution of abrasive tools, grit size of abrasives on surface characteristics of gears. They compared the surface textures produced by grinding and PECMP and it was found that the surface microtopography of surface polished by grinding is mild wave type where the microtopography of surface polished by PECMP is of plateau type. The results showed that the PECMP surfaces have more advantages over traditionally polished surfaces in respect of friction factor reduction, precision keeping, and anti-conglutination. These surface characteristics can improve the fatigue life and in-service performance of gears.

According to the best knowledge of authors, in India, the research on ECH was started in IIT Roorkee as Fasil (2004) and Dubey (2006) have studied the effect of various process parameters in ECH of internal cylinders. However, in IIT Roorkee, ECH of gears was initiated by Naik (2008) as he studied the effect of finishing time, current, electrolyte composition and electrolyte concentration after modifying the experimental setup of ECH of internal cylinders developed by Dubey in experimental setup for precision finishing of spur gears by ECH. The experimental study was designed using Taguchi's experimental design technique ( $\mathrm{L}_{9}$ Orthogonal Array). It is described that the parameters have significant effect on process performances. Microhardness values of gear teeth surface were evaluated to show that the process have no significant effect on hardness of workpiece. He has also explained the time dependent behaviour of ECH process. The results were analyzed by F-Test and Duncan's multiple range tests. Based on the results, it was found that six minute is optimum for the study and at optimum setting, the process showed an overall improvement of $80 \%$ and $67 \%$ in $R_{a}$ and $R_{t}$ respectively. Misra (2009), Singh (2010) and Misra et al. (2010a, 2010b) have carried out systematic investigation on ECH of helical gears and $\mathrm{PECH}$ of spur gears as described below.

\subsection{ECH of helical gears}

An experimental investigation has been carried out by developing an experimental setup to study the effects of finishing time, electrolyte related parameters (i.e. electrolyte temperature, electrolyte composition and electrolyte concentration), voltage and rotating speed of workpiece on the improvement of surface quality of helical gear teeth profiles finished by ECH process. The developed experimental setup consists of five major subsystems: power supply system, electrolyte supply system, tooling system, tool motion system and machining 
chamber (Misra et al., 2010). Power supply unit is used to supply a low DC voltage (3-40 V) and constant or pulsating current (up to $200 \mathrm{~A}$ ) across the electrolyte flooded IEG. The positive terminal of the supply is connected to the workpiece gear while the negative terminal is connected to the cathode gear. Electrolyte supply system consists of electrolyte reservoir, settling tank, pump, heat exchanger, flow meter, flow valves etc. The tooling system is the one which distinguishes between ECH of internal cylinders and ECH of gears. The tooling system for ECH of gears consists of three gears: cathode gear, honing gear and workpiece gear. Cathode gear is developed by sandwiching a gear of conducting material between two insulating gears and undercutting the profile of conducting gear to provide an IEG between workpiece gear and cathode gear while meshing to prevent short-circuit. Honing gear is used to provide mechanical abrasion action. The workpiece gear is placed in mesh in between the honing gear and cathode gear and a simultaneous rotational and reciprocating motion is supplied to the axle of workpiece gear by using a DC induction motor and a programmable stepper motor respectively. All gears are mounted on special type of axles made of stainless steel. Brackets are used for holding the gear axles of cathode and honing gears. Bakelite has been used as bracket material for its electrical insulation and corrosion resistance properties. The entire tooling system with axles is enclosed in a machining chamber made of perspex for better visibility and corrosion-resistance. Machining chamber also has provisions for supply of fresh electrolytes, for removal of used electrolyte, and for escape of gases generated during ECH process. Fig. 3 (a) shows the tooling system with machining chamber of developed setup.

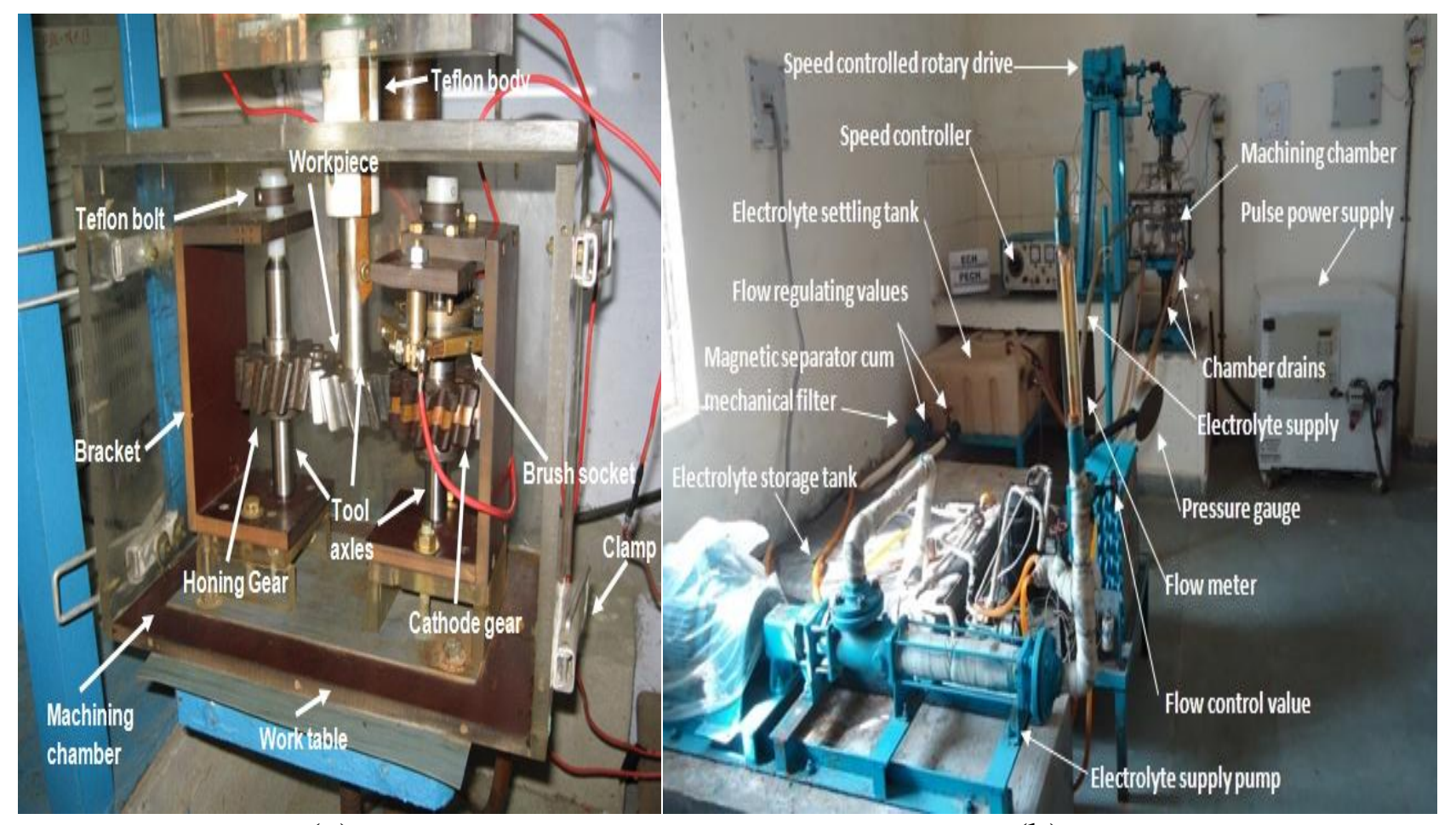

(a)

(b)

Fig. 3. (a) Tooling system with machining chamber for ECH of helical gears; (b) Developed experimental setup for PECH of spur gears 
In this work, percentage improvement in average surface roughness $\left(\mathrm{PIR}_{\mathrm{a}}\right)$ and maximum surface roughness $\left(\mathrm{PIR}_{\mathrm{tm}}\right)$ value have been used as the measures of process performance. Effects of finishing time, electrolyte temperature and electrolyte composition have been studied through pilot experiments by varying one variable at a time while, effects of voltage, rotating speed of workpiece gear and electrolyte concentration have been studied during the main experiments designed using BoxBehnken approach of response surface methodology (RSM). The effects of process parameters are shown in Fig. 4. PIR and $\mathrm{PIR}_{\mathrm{tm}}$ increase with the finishing time but at a decreasing rate because intensity of EC dissolution decreases as the surface gets smoothened. PIR and PIR $_{\mathrm{tm}}$ initially increase with voltage upto certain extent and then start decreasing indicating existence of an optimum value of voltage for achieving maximum value. In ECM process the volumetric MRR is proportional to the voltage but inversely proportional to the inter electrode gap (IEG). At the starting of the process, the surface is more irregular and therefore the rate of ECM process is also high. But after few cycles, ECM reduces the irregularities and increases the inter electrode gap results in deteriorating rate of ECM and decreasing volumetric MRR. The effect of rotating speed has low significant on average surface roughness. It shows the better result at the middle level. At low level, gears rotate at low speed. As a result, the ECM process has enough time to remove the material. But on the other hand, due to low speed the mechanical abrasion effect is negligible and not capable enough to fully remove the metal oxide micro film generated on work piece and decelerates the ECM process. At high level of rotating speed, though the mechanical abrasion effect is significant but ECM process does not get enough time to remove the material. An increase in electrolyte concentration improves the average surface roughness. As the concentration is increased, more number of ions is generated in the solution which results in increasing electrolyte conductivity and as a result increases in percentage improvement in average surface roughness value.

SEM photographs are taken (shown in Fig. 5) and optical profilometry (shown in Fig. 6) is conducted before and after the experimentation to identify the improvement of surface quality of helical gear teeth profiles after ECH process. Based on the results and desirability analysis, 7.5 minutes as finishing time, a mixture of $\mathrm{NaCl}$ and $\mathrm{NaNO}_{3}$ in a ratio of $3: 1,32{ }^{\circ} \mathrm{C}$ as electrolyte temperature, $27.57 \mathrm{~V}$ as voltage, $67.96 \mathrm{rpm}$ as rotating speed and electrolyte concentration of $10 \%$ are found optimum for precision finishing of helical gears. Using the results of main experiments, regression models have been developed for the measures of process performance (i.e. $\mathrm{PIR}_{\mathrm{a}}$ and $\mathrm{PIR}_{\mathrm{tm}}$ ). The developed regression models are depicted in eq. 1 and eq. 2. An analysis of variance (ANOVA) performed to test the significance of the developed models and process variables at 95\% confidence level found the developed models highly significant and found that voltage and electrolyte concentration have significant effect on the responses. However, no significant interaction effect has been observed. Predictions from the regression models have been validated by comparing them with the results of the confirmation experiments, which proves that the developed models are correct and acceptable. 


\subsection{PECH of spur gears}

The ECH process has also been carried out under pulse power supply for finishing spur gears to study the effect of pulsating current and it is found that the process shows better result than ECH of spur gears. An experimental setup, as shown in Fig. 3(b) has been developed to carry out experimental investigation on PECH of spur gears. Finishing time, electrolyte related parameters (i.e. electrolyte composition, electrolyte concentration, electrolyte temperature), current, duty cycle were used as input process variables to explore its effects on improvement of surface quality of gear teeth profile. The effects of parameters in $\mathrm{PECH}$ of spur gear are shown in Fig. 7. It was found that finishing time and electrolyte concentration show the same trend as shown in ECH of helical gears. Three different compositions of the mixture of $\mathrm{NaCl}$ and $\mathrm{NaNO}_{3}$ and pure $\mathrm{NaCl}$ were used as electrolyte for the study. It is evident from results, that mixture of $\mathrm{NaCl}$ and $\mathrm{NaNO}_{3}$ in 3:1 ratio gives better result as more number of ions for machining is available in the solution and for better passivation effect of the mixture. The surface finish improves with increasing electrolyte temperature. Electrolyte conductivity is very much sensitive towards electrolyte temperature and increases with it results in higher current density and thus provides the higher value of $\operatorname{PIR}_{a}$ and $\mathrm{PIR}_{\mathrm{tm}}$. But, at higher temperature chance of formation of hydrogen gas at cathode is higher. It deteriorates the surface finish. In $\mathrm{PECH}$, material removal rate increases with current density and as well as with duty

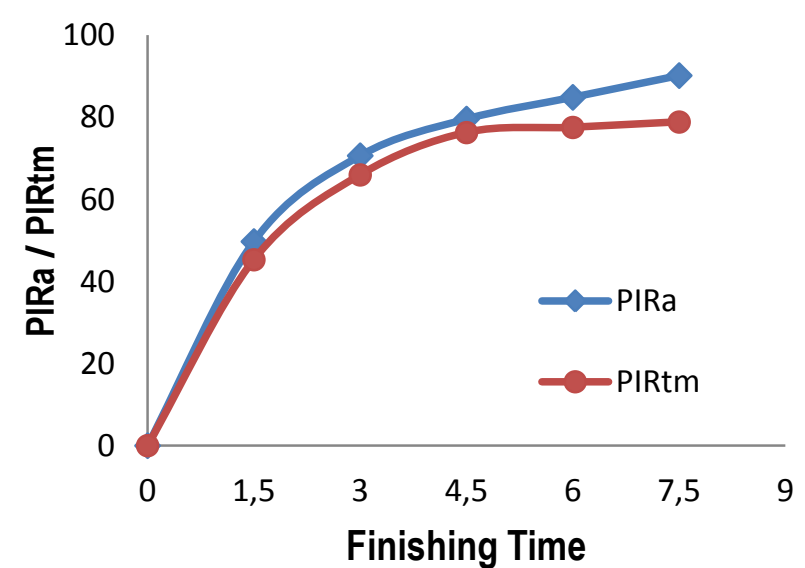

(a)

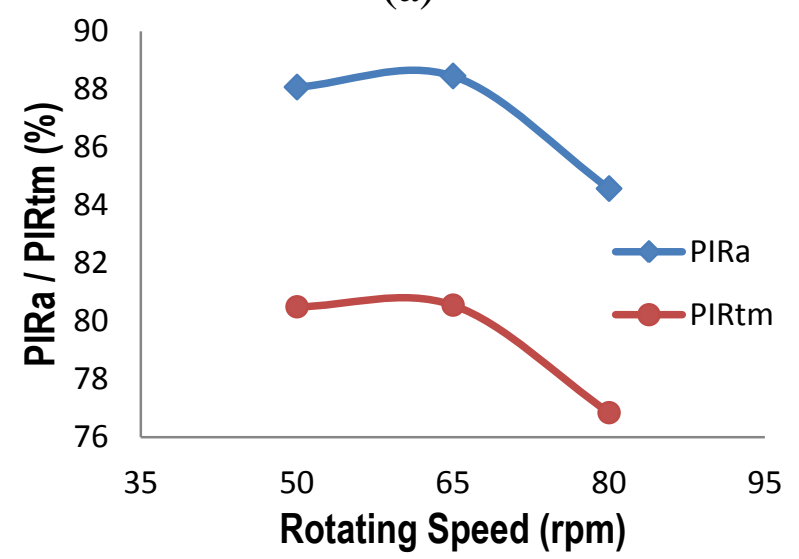

(c)

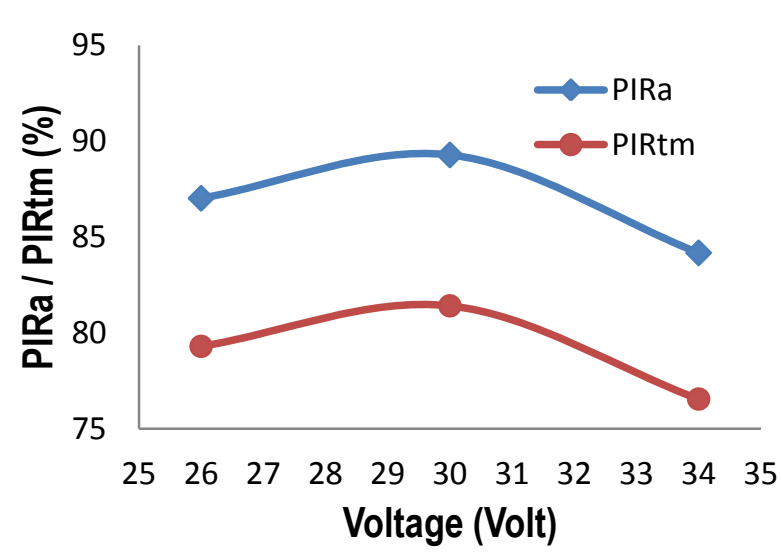

(b)

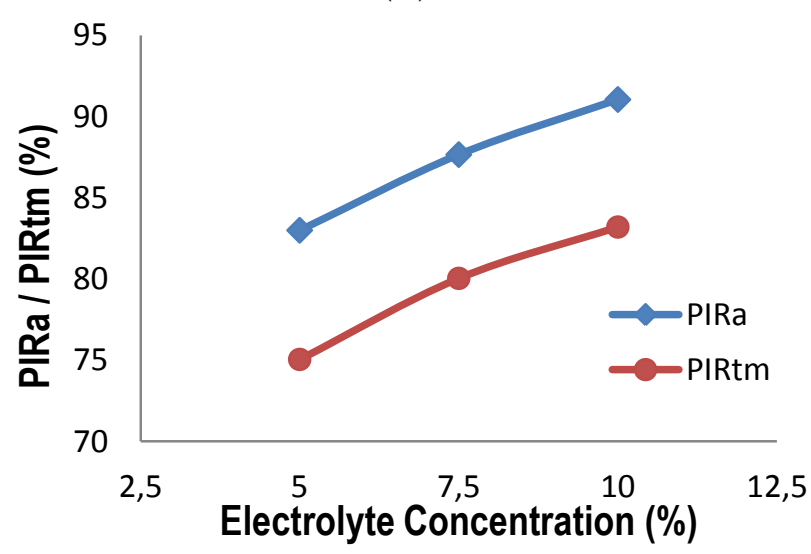

(d)

Fig. 4. The effects of parameters on PIR $\mathrm{P}_{\mathrm{a}}$ and PIR $\mathrm{t}_{\mathrm{tm}}$ in ECH of helical gears: (a) effect of finishing time; (b) effect of voltage; (c) effect of rotating speed and (d) effect of electrolyte concentration 
cycle. But, at higher duty cycle, the relaxation period of the system is low and it is very much difficult for the process to remove the dregs completely from electrodes' gap. Duty cycle of $22.20 \%$ is found optimum for PECH of spur gears. It is evident from Fig. 7 that both PIR $_{\mathrm{a}}$ and PIR $_{\mathrm{tm}}$ initially increases with current up to a certain extent and then start decreasing indicating an existence of optimum value. This can be explained as follows: in ECM, the volumetric material removal rate is proportional with the current but it is inversely proportional with the inter electrode gap (IEG). At the start of the PECH process, the surface is more irregular and therefore the rate of ECM is also high. But after few cycles, ECM reduces the irregularities and increases the IEG thereby decreasing volumetric material removal rate.

SEM micrographs are presented in Fig. 5 to depict the potential of the process in improving the surface characteristics of PECHoned gears. Regression models have been also developed and presented in eq. 3 eq. 4 .

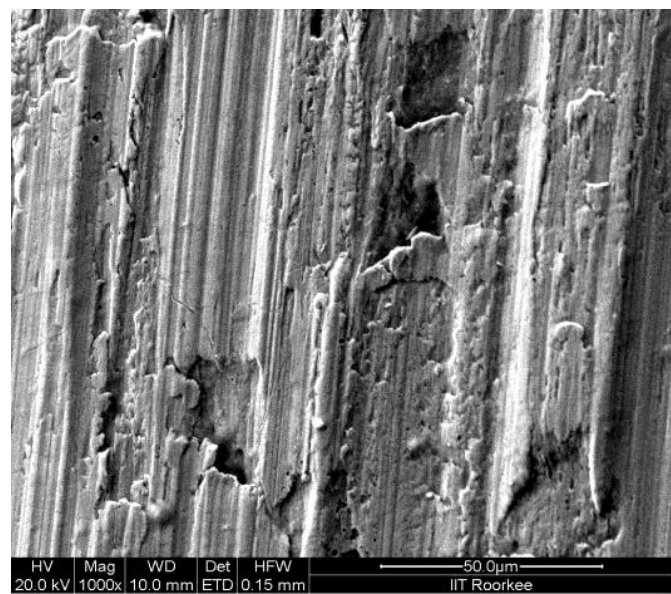

(a)

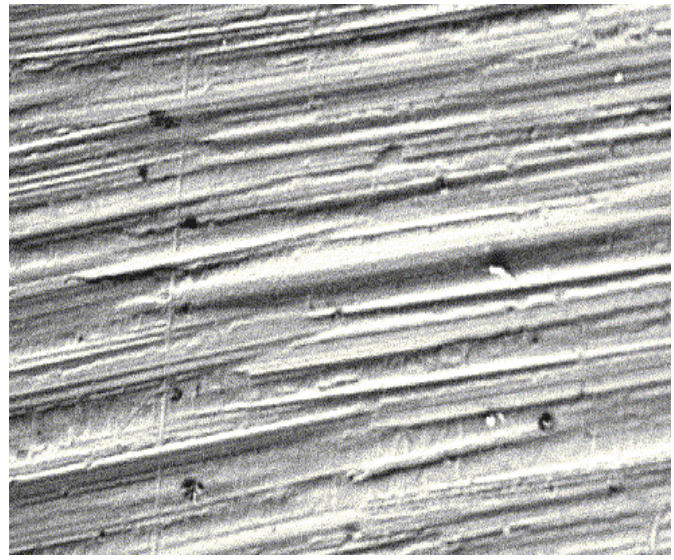

(c)

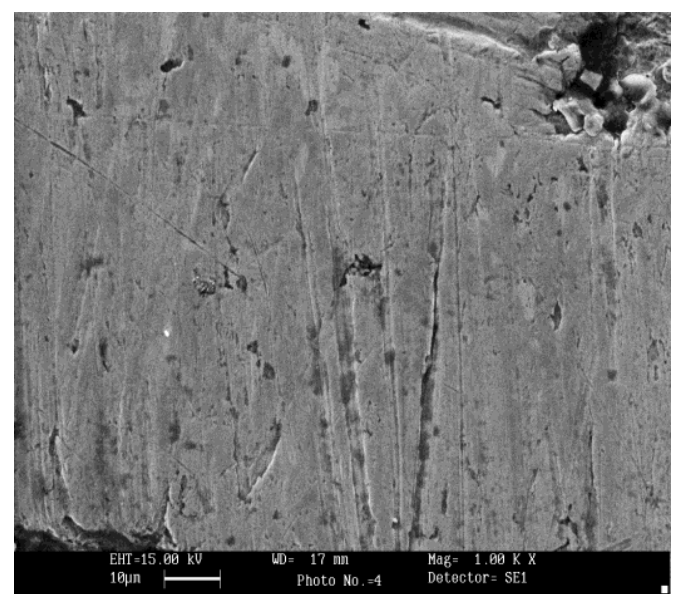

(b)

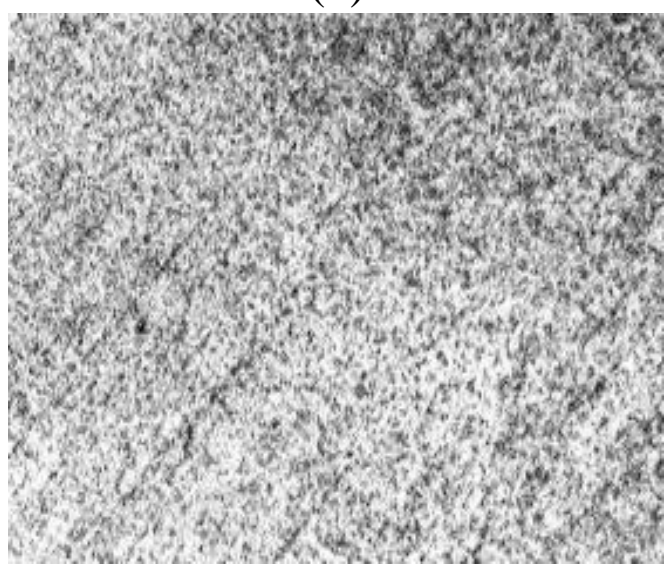

(d)

Fig. 5. SEM Micrographs of gear teeth surface (a) before ECH (At 1000x magnification); (b) after ECH (At 1000x magnification); (c) before PECH (At 500x magnification); (d) after PECH (At 500x magnification)

$\mathrm{PIR}_{\mathrm{a}}($ In ECH of helicale gear $)=-173.75771+13.90969 *$ Voltage $+1.43058 *$ Rotating Speed $+4.27700 *$ Electrolyte Concentration $-0.24563 *$ (Voltage $^{2}$ -

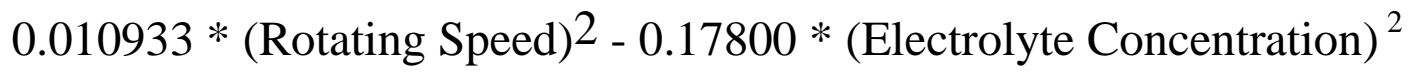


$\mathrm{PIR}_{\mathrm{tm}}($ In ECH of helicale gear $)=-167.99383+13.08875 *$ Voltage $+1.33719 *$ Rotating Speed $+4.84850 *$ Electrolyte Concentration $-0.23315 *(\text { Voltage })^{2}$ $0.010080 *(\text { Rotating Speed })^{2}-0.21447 *{\text { (Electrolyte Concentration })^{2}}^{2}$

PIR $_{\mathrm{a}}($ In PECH of spur gear $)=-60.24529+1.98545 *$ Current $+10.40198 *$ Pulseoff Time $+84.07185 *$ Pulse-on Time $+1.61767 *$ Electrolyte Concentration $0.044407 *(\text { Current })^{2}-1.00299 *(\text { Pulse-off Time })^{2}-23.51284$ (Pulse-on Time $)^{2}$

$\mathrm{PIR}_{\mathrm{tm}}$ (In PECH of spur gear $)=-3.38531+2.46858 *$ Current $-1.66521 *$ Pulseoff Time $+92.91333 *$ Pulse-on Time $-6.26683 *$ Electrolyte Concentration $0.056188 *(\text { Current })^{2}-0.97281 *(\text { Pulse-off Time })^{2}-26.56000 *{\text { (Pulse-on Time })^{2}}^{2}$ $+1.48950 *$ Pulse-off Time * Electrolyte Concentration

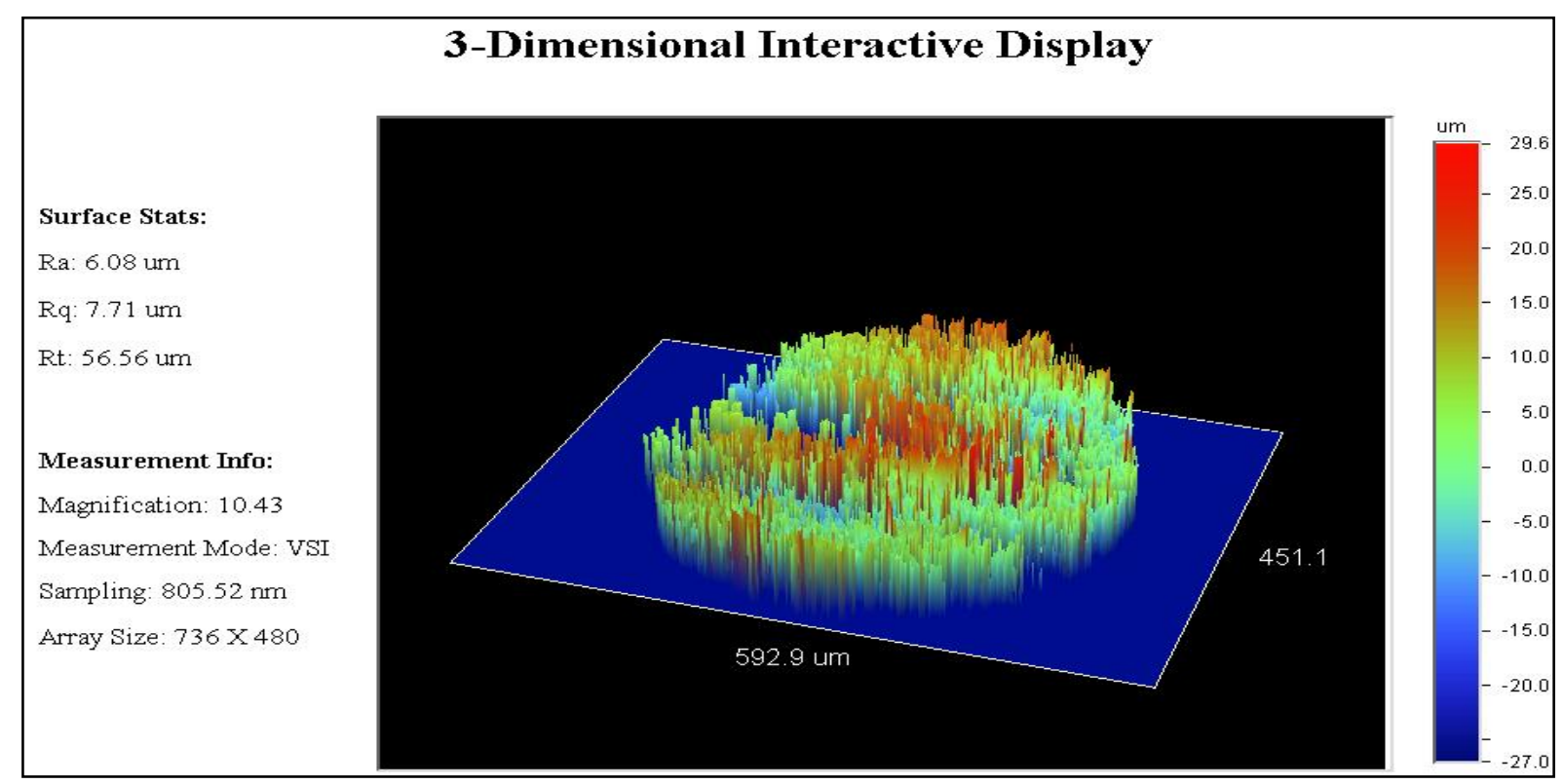

(a)

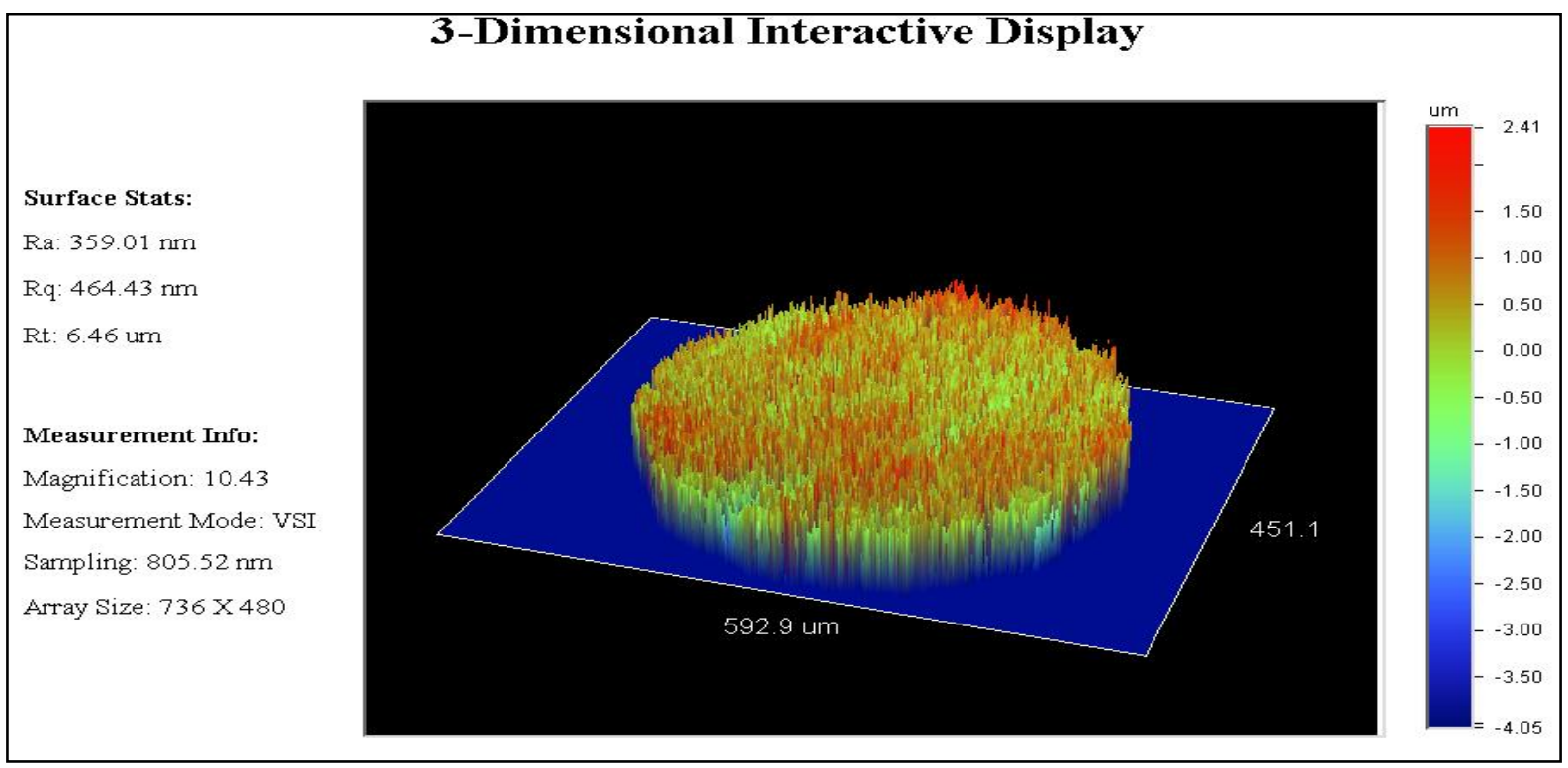

(b)

Fig. 6. Three dimensional plot of work-surface taken by optical profilometer (a) before $\mathrm{ECH}$ and (b) after $\mathrm{ECH}$ 


\section{Conclusions and Future Scope}

$\mathrm{ECH}$ is one of the most potential hybrid machining processes and combines the controlled electrolytic dissolution and mechanical abrasion in single operation. The efficiency of the process in correcting micro and macro-geometric errors of gear teeth profile depends on the proper co-ordination of both the action. In the present work, the detail description of the process principle, process parameters, material removal mechanism has been described with elaborate review of past research works. It is evident from the experimental investigation that the process is highly capable of improving the surface integrity of gear teeth surface and consequently the service life of critical components. Thus, the process is very much useful for improving the fatigue life and service life of gears and it can be concluded that the process is a recent trend of advanced gear finishing processes. However, the developed experimental setup is not capable to accommodate the gear of different sizes and therefore, a vigorous study is required to develop an experimental setup with modular tooling system to accommodate gear of different sizes and to carry out ECM, honing and $\mathrm{ECH}$ process in a single setup to transform it into a matured manufacturing technology and for its successful industrial applications and commercialization. Moreover, like most of the hybrid machining processes (HMPs), ECH of gears is also in the infancy stage and therefore a sustained global research is required.

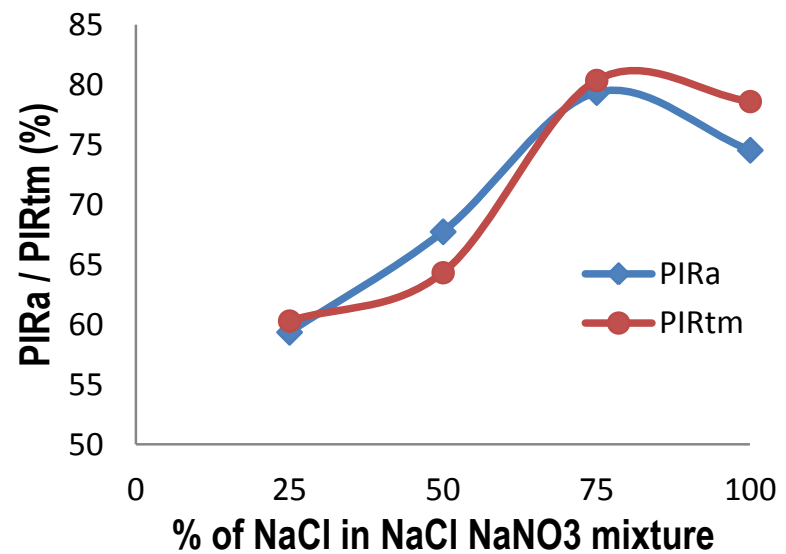

(a)

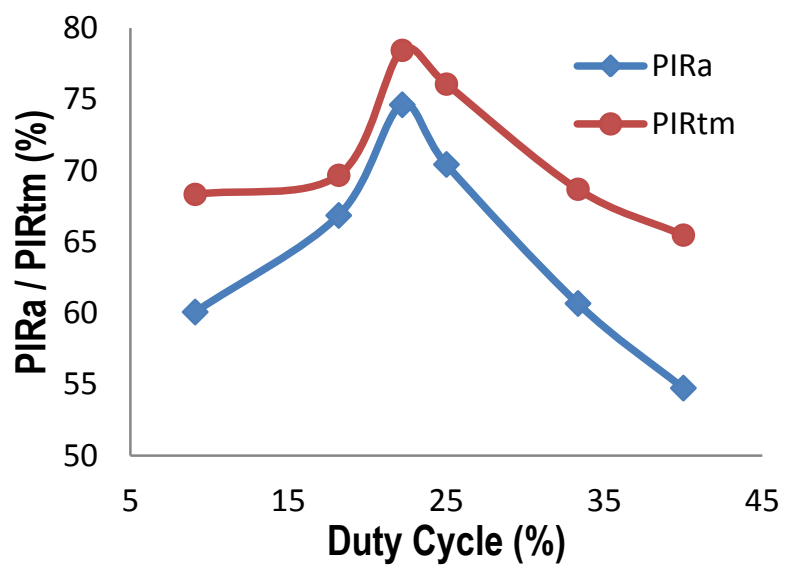

(c)

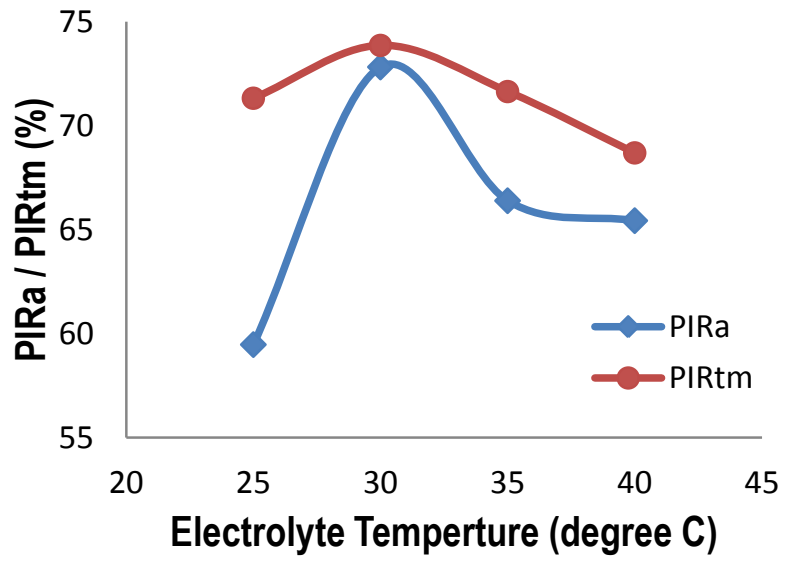

(b)

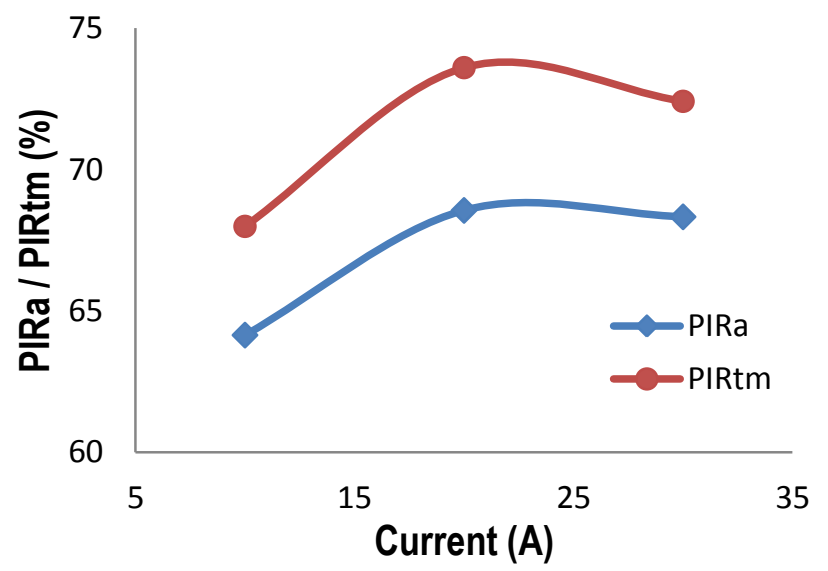

(d)

Fig. 7. The effects of parameters on PIR and PIR ${ }_{t m}$ in PECH of spur gears: (a) effect of electrolyte composition; (b) effect of electrolyte temperature; (c) effect of duty cycle and (d) effect of current 


\section{References}

Benedict, G. F. (1987). Nontraditional Manufacturing Processes, Marcel Dekker, 0824773527, New York

Bralla, J. G. (1986). Handbook of Product Design for Manufacturing, Mc Graw-Hill, 0070071306, New York

Budzynski, A. F. (1978). Electrochemical Honing Machine. Polish Technical Review, Vol. 12, 2-3

Budzynski, A. F. (1980). Theoretical principles and technical factors of electrochemical honing. International Symposium on Electro Machining (ISEM)-6, Krakow

Capello, G. \& Bertoglio, S. (1979). A New Approach by Electrochemical Finishing of Hardened Cylindrical Gear Tooth Face. CIRP Annals, Vol. 28, No. 1, 103107, 00078506

Chen, C. P.; Liu, J.; Wei, G. C.; Wan, C. B. \& Wan, J. (1981). Electrochemical Honing of Gears: A New Method of Gear Finishing. CIRP Annals, Vol. 30, No.1, 103-106, 00078506

Davis, J. R. (2005). Gear Materials, Properties, and Manufacture, ASM International, 0871708159, Ohio

Drozda, T. (1983). Tool \& Manufacturing Engineers Handbook Vol.1: Machining, Society of Manufacturing Engineers, 0872630854, Michigan

Dubey, A. K. (2006). Development of the setup and performance optimization of electrochemical honing process. Ph.D. Thesis, Mechanical \& Industrial Engineering Department, IIT Roorkee

Dudley, D. W. (1984). Handbook of Practical Gear Design, McGraw-Hill, 0070179514, New York

El-Hofi, H. (2005). Advanced Machining Processes, McGraw-Hill, 0071453342, New York

Eshelman, R. H. (1963). Electrochemical Honing Reports Ready for Production Jobs. Iron Age, 124

Fasil, T. (2004). Parametric optimization of electrochemical honing. M.Tech Dissertation, Mechanical \& Industrial Engineering Department, IIT Roorkee.

Goch, G. (2003). Gear Metrology. CIRP Annals, Vol. 52, No. 2, 659-695, 00078506

He, F.; Zhang, W. \& Nezu, K. (2000). A Precision Machining of Gears (A Slow Scanning Field Controlled Electrochemical Honing). JSME International Journal Series C, Vol. 43, No. 2, 486-491, 13447653

Horgan, I. F. (1962). Electrolytic boost for honing. American Mach.

Jianjun, Y.; Yujie, D.; Shaohua, Z.; Baiyangand, J. \& Jingjing, Z. (2009). A Novel Technique of Polishing Gear Working Surface Using PECMP. International Journal of Precision Engineering and Manufacturing, Vol. 10, No. 4, 57-62, 20054602

Karpuschewski, B.; Knoche, H. -J. \& Hipke, M. (2008). Gear Finishing by Abrasive Processes. CIRP Annals, Vol. 57, No. 2, 621-640, 00078506.

Klocke, F. (2009). Manufacturing Processes 2, Springer-Verlag, 9783540922599, Berlin 
Machinability Data Center. (1980). Machining Data Handbook 3rd Edition, Vol 2, Metcut Research Associates Inc., 0936974028, Ohio

McGeough, J. (1974). Principles of Electrochemical Machining, Chapman and Hall, 0412119706, London

Misra, J. P. (2009). Precision finishing of helical gears by electrochemical honing (ECH) process. M.Tech Dissertation, Mechanical \& Industrial Engineering Department, IIT Roorkee

Misra, J. P.; Jain, N. K. \& Jain, P. K. (2010). Investigations on precision finishing of helical gears by electrochemical honing (ECH) process, Proc. IMechE: Journal of Engineering Manufacture, Vol. 224, No. 12, 1817-1830, 20412975

Misra, J. P. \& Jain, P. K. (2010). Experimental Investigation on Precision Finishing of Spur Gears by Pulse Electrochemical Honing (PECH) Process, Annals of DAAAM for 2010 \& Proceedings of the 21st International DAAAM Symposium, Katalinic, B. (Ed.), pp. 1051-1052, ISBN 978-3-901509-73-5, DAAAM International, Vienna, Austria

Naik, L. R. (2008). Investigation on precision finishing of gears by ECH. M.Tech Dissertation, Mechanical \& Industrial Engineering Department, IIT Roorkee.

Oberg, E.; Jones, F. D.; Horton, H. L. \& Ryffel, H. H. (2008). Machinery's Handbook $28^{\text {th }}$ Edition, Industrial Press, 9780831128012, New York

Pandey, P. C. \& Shan, H. S. (1980). Modern Machining Processes, Tata McGrawHill, 0070965536, New Delhi

Randlett Jr., E. A. \& Ellis, M. P. (1967). Electrochemical Honing. American Society of Tools and Manufacturing Engineers (ASTME), Technical Paper MR67-648, $1-13$

Randlett Jr., E. A. \& Ellis, M. P. (1968). Electrochemical Honing - ECH. American Society of Tools and Manufacturing Engineers (ASTME), Technical Paper MR68-815, 1-11

Singh, H. (2010). Experimental investigation of precision finishing of spur gears by pulse-electrochemical honing $(\mathrm{PECH})$ process. M.Tech Dissertation, Mechanical \& Industrial Engineering Department, IIT Roorkee

Wei, B. Y.; Dengand, X. Z. \& Fang, Z. D. (2007) Study on ultrasonic-assisted lapping of gears. International Journal of Machine Tools and Manufacture, Vol. 47, No. 12-13, 2051-2056, 08906955

Wei, G.; Wu, M. \& Chen, C. (1986). An Investigation into the Ability of Correcting Error in ECH. CIRP Annals, Vol. 35, No. 1, 125-127, 00078506.

Wei, G.; Wang, Z. \& Chen, C. (1987). Field Controlled Electrochemical Honing of Gears. Precision Engineering, Vol. 9, No. 4, 218-221, 01416359

Wilson, J. F. (1971). Practice \& Theory of Electrochemical Machining, John Wiley, 0471949701, New York

Yi, J.; Yang, T. \& Zhou, J. (2000). New electrochemical processes gear tooth-profile modification. Mfg. Tech. and Modern Machine, Vol. 9, No. 1, 102-105

Yi, J.; Zhang, J.; Yang, T.; Xia, D. \& Hu, D. (2002). Solving the control problem for electrochemical gear tooth-profile modification using an artificial neural network. International Journal of Advanced Manufacturing Technology, Vol. 19, No. 1, 8-13, 14333015 